\title{
Research on the Integrational Route of Ideological and Political Education and Mental Health Education in Higher Vocational Colleges Based on Synergy Theory
}

\author{
Li Jingmin $^{1, a}$ \\ ${ }^{1}$ Students' Affairs Division, Tianjin Vocational Institute, Beichen District, Tianjin, China \\ alijingmin0917@163.com
}

\begin{abstract}
The development stage of college students is an important period of self-development and personality improvement, and a critical stage of establishing world outlook, outlook on life and values. But with the rapid development of economy and the popularization of information network, the ideological and psychological problems of students in higher vocational colleges are more diversified and complicated. For higher vocational colleges, how to improve the effectiveness of ideological and political education and mental health education, and promote the healthy development of students is an important issue to be solved. Based on the Synergy Theory, this paper analyzed the theoretical basis and practical needs of the integration of ideological and political education and mental health education, and the relationships between them and the significance of their combination. In addition, the paper explored the path of synergetic education in higher vocational colleges, to improve the effectiveness of education and promote the overall development of students.
\end{abstract}

Keywords: Synergy Theory, higher vocational colleges, ideological and political education, mental health education

\section{协同理论视域下高职院校思想政治教育与心理健康教育 融合路径探析}

\author{
李敬敏 $1, \mathrm{a}$
}

${ }^{1}$ 天津职业大学学生处, 北辰区, 天津, 中国

a lijingmin0917@163.com

\section{摘要}

大学生阶段是自我发展、人格完善的重要时期, 也是树立世界观、人生观、价值观的关键阶段。但是 随着经济的快速发展和信息网络的普及化, 高职学生的思想问题和心理问题越来越多元化和复杂化。 对于高职院校来说, 如何提高思想政治教育和心理健康教育的实效性, 促进学生健康发展是当前亟待 解决的重要课题。本文是基于协同理论, 分析思想政治教育与心理健康教育融合的理论基础和现实需 求, 分析两者的关系以及结合的意义, 并在高职院校中探索两者融合的路径, 从而发挥协同育人作用, 提高教育实效性、促进学生全面发展。

关键词：协同理论，高职院校，思想政治教育，心理健康教育

\section{1. 引言}

当前, 随着经济发展的加快和社会竞争的日益激烈, 大学生面临着理想信念、价值取向的极大考验, 各种压
力也日益剧增。由于大学生所处的特殊发展阶段, 是认 识自我形成自我统一性, 人格完善的关键时期, 也是形 成稳定的价值观、人生观、世界观重要阶段, 特别容易 产生心理困惑和冲突。面对信息网络的发展以及多元文 化的冲击, 大学生的思想问题和心理问题越来越复杂化 
较差, 很容易被享乐主义和拜金主义思想侵蚀, 缺乏集

和多元化。高职院校是为国家经济发展培养技术技能型 人才的学校, 由于社会认可度等问题, 与本科生相比, 高职学生面临着更多心理压力和思想问题。

高校思想政治教育工作的目标是为社会主义事业 培养德智体美劳全面发展的建设者和接班人。面对新的 形势, 高校思想政治教育工作如何跟上改革和发展的步 伐,引导学生在思想、观念、心理上尽快适应新的要求, 这是高校思想政治教育工作在新新形势、新情况下面临 的严峻考验（郭汉军，2008）。而高职院校长期以来更 多是重视学生专业技术技能的掌握, 对于学生人文教育 和精神教育方面相对重视不足, 思想政治教育和心理健 康教育的发展相对比较滞后。为了突破思想政治教育工 作困境, 需要全面了解学生基础上满足学生发展需求, 因此将心理健康教育相关理念知识和方法融入到思想 政治教育之中发挥协同育人作用, 将是增强思想政治教 育针对性和实效性, 促进学生健康成长的有效途径。

\section{2. 思想政治教育与心理健康教育融合的理 论基础与现实需求}

\section{1 理论基础}

协同理论（synergetics）, 又称协同学或协和学, 是在多学科研究基础上形成和发展起来的, 研究不同事 物共同特征及其协同机理的一门新兴学科, 是由著名物 理学家赫尔曼・哈肯（Hermann Haken）在 20 世纪 70 年代提出的 (向芬, 2016)。协同理论着重探讨各种系 统从无序变为有序时的相似性, 具有普适性特征, 是探 索未知领域的有效手段。协同理论认为, 千差万别的系 统, 尽管其属性不同, 但在整个环境中, 各个系统间存 在着相互影响而又相互合作的关系, 协同就是要在各子 系统之间构建起协调一致的目标追求, 以利于各子系统 的优化组合和协同效果达到最优，从而实现系统的共同 目标（王海建，2013）。思想政治教育和心理健康教育 在理论基础、指导思想、评估标准等方面存在着差异性, 但是两者具有一致的教育目标和相同的教育对象, 教育 内容又有所交叉（向芬，2016）。因此根据协同理论, 思想政治教育与心理健康教育既有差异性又有同一性 的关系为两者融合发挥协同作用提供了必要的基础和 前提。

\section{2 现实需求}

从高职学生所处的发展阶段来看, 学生情绪调节不 稳定, 情感体验强烈, 自我控制能力较差, 很容易受到 外界环境的影响产生冲动行为。近几年, 大学生群体中 违法犯罪问题、暴力伤人事件以及自杀危机事件的频频 发生, 引起社会各界的广泛关注。在经济发展逐步加快 和信息网络迅速发展的背景下, 由于高职学生长期处在 家长和学校的保护中, 自身抗干扰能力和明辨是非能力
体主义观念, 缺乏艰苦奋斗精神。因此, 新形势下高职 学生存在的心理问题和思想问题, 是学校思想政治教育 和心理健康教育面临的困境, 也是亟待解决的重要课题。

从教育的实际效果来看, 传统的思想政治教育途径 比较单一, 教育方式主要以理论说教和灌输式教育为主, 教育内容枯燥很难真正让学生入脑入心, 难以满足学生 的发展需求和现实需要, 因此导致思想政治教育的实效 性并不强, 很多时候存在形式强于效果的现象。近 30 年来, 心理健康教育快速发展, 但是在高职院校中产生 的效果并不明显, 原因可能在于: 一方面高职院校中专 门从事心理健康教育的师资力量比较薄弱, 虽然大多按 照师生比 1: 4000 的比例配备专职心理教师, 但是考虑 到学生的数量与实际需求, 常规的心理咨询可能并不能 解决大多数学生的问题; 另一方面可能是高职学生对心 理健康的重视性不足, 并且受传统思想的影响对心理咨 询没有形成正确合理的认识, 遇到问题很少人能够主动 寻求心理教师的帮助。

因此, 在协同理论的基础上, 在高职院校中发挥思 想政治教育和心理健康教育的协同作用, 是解决学生心 理问题和思想问题, 促进学生健康成长的现实需要, 也 是创新教育方式方法, 解决思想政治教育的现实困境, 提高思想政治教育实效性的现实需要。

\section{3. 思想政治教育与心理健康教育的关系与 协同的意义}

\section{1 思想政治教育与心理健康教育的差异性 与同一性}

高校思想政治教育是以马克思主义基本立场、观点 和方法, 针对大学生思想变化的特点和发展规律, 综合 运用相关学科知识, 教育引导广大学生树立正确的世界 观、人生观和价值观, 树立爱国主义、集体主义和社会 主义思想, 培养学生高尚的道德情操 (李晓莉, 2007)。 高校心理健康教育是运用心理学的理论和方法, 通过心 理辅导和心理咨询的方式解决学生心理问题和心理困 扰, 并通过日常教育、教学活动等加强心理知识宣传, 从而提高学生心理保健意识, 提高学生的心理健康素质, 促进学生人格完善, 实现身心和谐发展。

从概念上来看二者在指导思想和理论基础上是有 差异的, 同时在教育方式和工作方法上也有很大差别。 高校思想政治教育更多是理论灌输和外在教化为主, 具 有普及性与开放性, 注重社会和集体的发展, 把学生当 做“社会人”, 使学生顺利完成社会化, 被社会所认同; 而心理健康教育更多是情感疏导和心理关怀为主, 更加 注重个体的内在感受和内在需求, 强调个体意愿和保密 性, 把学生看作 “个性化” 的人, 关注个体的健康成长。 同时在价值导向和评判标准上两者也有差别, 思想政治 教育属于意识形态教育, 具有明确的价值导向, 是按照 社会需要塑造人才, 强调个人行为规范符合社会道德标 
理咨询也存在一些偏见, 遇到问题大多不会主动求助心 理中心, 而心理问题严重或患有心理疾病的学生大多是 直接休学或退学。心理健康教育在高职院校中有被边缘 化的倾向, 面对众多潜在心理问题学生心理教师往往力 不从心。相对来说, 思想政治教育更成体系, 学生必修 的思政课程较多, 日常的思想政治教育活动也很丰富。 从事思想政治教育的队伍相对也比较壮大,包括思政课 教师、辅导员、班主任、政工干部等, 这也为心理健康 教育的发展提供了师资保障。因此，心理健康教育可以 借助思想政治教育课程教学和日常活动平台, 开展心理 健康知识宣传和辅导活动, 服务对象由问题学生转变为 全体学生, 从而加强心理健康教育的普及化和大众化, 促进心理健康教育的发展。

\section{4. 思想政治教育与心理健康教育融合的路 径探析}

\section{1 树立思想政治教育与心理健康教育协同 育人的理念}

思想政治教育与心理健康教育的协同作用, 是解决 学生问题促进学生健康成长的迫切需要, 也是突破思想 政治教育和心理健康教育困境, 增强教育实效的必然选 择。思想政治教育和心理健康教育的目的都是为了培养 学生成为具有良好的道德素质和心理素质的合格人才, 并不是单纯的知识教育和宣传教育, 促进学生个人成长 与提升才是两者的根本出发点 (申青, 2013)。因此在 高职院校探索其有机融合的路径时, 首先就是要树立协 同育人的理念, 转变只重视培养学生技术技能而轻视学 生精神人文教育的办学方式, 真正树立以生为本的理念, 打破传统的思想政治教育观，充分重视思想政治教育和 心理健康教育对学生的引导作用, 紧紧围绕培养高素质 技术技能人才为统一目标, 从而统筹一切有利于学生健 康成长和全面发展的因素, 使思想政治教育和心理健康 教育在课程设置、师资力量、教育方式等方面相互作用、 相互促进，共同发挥协同育人作用。

\section{2 营造思想政治教育与心理健康教育协同 育人的文化氛围}

丰富的校园文化活动和实践活动是进行思想政治 教育和心理健康教育的重要渠道。在实际工作中, 可以 发现很多学生参加活动的主动性和积极性不高, 更多是 为了 “学分” 被动参加, 不能真正投入参与, 不能体会 到活动的意义, 精心策划的活动往往达不到理想的效果, 思想政治教育与心理健康教育的融合是打破此困境的 有效途径。首先, 应该改变活动设计理念, 把学生的现 实需求作为首要考虑, 活动之前开展调查研究, 充分了 解学生的需求和乐于接受的方式, 而不是组织者单方面 的以自己的意愿设计活动。其次, 在高职院校中学生自 
了解学生心理和思想状况, 建立学生个人档案, 使思想 政治教育更加符合教育规律和学生特点, 从而提高教育 的针对性。心理健康教育可以借鉴思想政治教育的方法, 积极主动宣传, 开展多种形式教育活动, 帮助学生树立 对心理咨询和心理辅导的正确观念, 重视自身心理健康。 同时面对学生心理困扰时, 学会从思政角度、社会角度 等考虑问题, 注重学生人生观、价值观的提升, 扩展心 理健康教育的广度和深度。在高职院校中, 心理咨询往 往达不到理想的效果, 学生更多依赖直接指导和建议, 因此在工作中可以更多的采用榜样示范教育和团体小 组活动, 注重对学生干部和学生社团心理知识方面的培 训, 依靠朋辈力量, 让学生在群体中得到成长。

\section{项目基金}

本文为天津职业大学校基金项目《高职院校中学生思想 政治教育与心理健康教育整合策略的探究》(20183105)

\section{REFERENCES}

[1] Guo, H.J. (2008) The effective role of mental health education to strengthen the ideological and political education of college students. Journal of Xinjiang University (Philosophy, Humanities \& Social Sciences), 05:38-41.

[2] Xiang, F. (2016) The integration of ideological and political education and mental health education of college students based on coordination. Theory Research. 07:248-249.

[3] Wang, H.J. (2013) Collaborative nnovation: the inevitable path of innovation and development of deological and political education in colleges and universities. Probe. 01:193-143.

[4] Li, X.L. (2007) Discussion on the integration of ideological and political education and mental health education in colleges and universities. Education and Vocation. 06:78-79.

[5] Xu, W., Wang, Y.F. (2018) Based on consciousness structure: deep integration of ideological and political education and mental health education in colleges and universities. Hubei Social Sciences. 04:188-192.

[6] Li, C.S., Shang, L. (2013) A study of differences and fusions between college mental health education and ideological and political education. Theory Research. 026: 374-375.

[7] Shen, Q., Li, X.E. (2013) A study on the synergistic effect of ideological and political education and mental health education in colleges and universities. Forward Position. 09:42-44.

[8] Liu, Y. (2005) The preliminary analysis of incorporating university's mental health education into ideological and political education. Journal of Zhenjiang College. 03:86-89. 